\title{
Neuroretinitis with dual infections
}

This article was published in the following Dove Press journal:

International Medical Case Reports Journal

19 October 2015

Number of times this article has been viewed

\section{Kwong-Han Kiu ${ }^{1,2}$ \\ Hashim Hanizasurana' \\ Embong Zunaina ${ }^{2}$ \\ 'Department of Ophthalmology, Hospital Selayang, Selayang, Selangor, \\ ${ }^{2}$ Department of Ophthalmology, School of Medical Sciences, Universiti Sains Malaysia, Kubang Kerian, Kelantan, Malaysia}

Correspondence: Kwong-Han Kiu Department of Ophthalmology, School of Medical Sciences, Universiti Sains Malaysia, I6I50 Kubang Kerian, Kelantan, Malaysia

Tel +609767 6362

Fax +609765 3370

Email kiukh@hotmail.com
Abstract: A 22-year-old Malay female presented with left eye floaters for 2 weeks, associated with temporal visual field defect and metamorphopsia for 3 days. She has a guinea pig and a hedgehog at home, but denied being bitten or scratched by them. Her visual acuity at presentation was $6 / 12$ on the left eye and 6/6 on the right eye. Her left eye relative afferent pupillary defect was barely positive with mild anterior chamber reaction. Fundus examination of the left eye showed mild vitritis, swollen optic disc with macular star, crops of active choroidal lesions at superonasal retina with a linear arrangement in the form of migratory track nasally. However, there were no nematodes seen on fundus examination. Investigations showed normal full blood count with no eosinophilia and positive serology test for Bartonella henselae. She was diagnosed to have dual infection - diffuse unilateral subacute neuroretinitis (DUSN), based on the presence of crops of choroidal lesions with migratory track, and cat scratch disease (CSD) based on a positive serological test. She was treated with oral albendazole $400 \mathrm{mg} 12$ hourly for 6 weeks for DUSN and oral doxycycline $100 \mathrm{mg} 12$ hourly for 4 weeks for CSD. Focal laser had been applied to the area of migratory track in the left eye. Her left eye vision improved to 6/6 at 1 month after treatment, with resolution of neuroretinitis.

Keywords: neuroretinitis, diffuse unilateral subacute neuroretinitis, bartonellosis, cat scratch disease

\section{Introduction}

Neuroretinitis is a disease entity in which there is an inflammatory disorder characterized by optic disc edema and macular star. ${ }^{1}$ It was originally described by Leber ${ }^{2}$ in 1916 as stellate maculopathy, but Don Gass ${ }^{3}$ in 1977 found it to be due to leakage from the optic disc. The underlying pathophysiology involves increased permeability of disc vasculature with exudation of fluid into the peripapillary retinal. ${ }^{4}$ It can be caused by infection or can be idiopathic. Common infections that cause neuroretinitis are cat scratch disease (CSD), syphilis, burkholderia, and leptospirosis. ${ }^{4,5}$ Other causes include toxoplasmosis, tuberculosis, and histoplasmosis. ${ }^{5,6}$ It is rarely caused by nematodes or diffuse unilateral subacute neuroretinitis (DUSN). ${ }^{7}$ Hence, a complete diagnostic examination in patients presenting with acute neuroretinitis should include a thorough history and general medical evaluation. Exposure history should be thoroughly explored, including details about recent travel, unpasteurized and uncooked foods consumed, sexual experience, and animal contacts. Detailed physical examination and laboratory tests tailored to the history and examination should be performed to aid in diagnosis.

We report a case of neuroretinitis, which involved two pathogens and discuss its features on presentation as well as serological importance in detecting the underlying pathogens. 


\section{Case report}

A 22-year-old Malay female without chronic systemic comorbidity presented with left eye floaters for 2 weeks. Later, she developed left eye temporal visual field defect and metamorphopsia for 3 days. However, there was no eye pain or eye redness. Further history revealed that she has a hedgehog and a guinea pig at home, but denied being bitten or scratched by them. She also denied any history of fever, recent traveling, sexual promiscuity, and oral intake of any uncooked food. Her visual acuity at presentation was $6 / 12$ in the left eye and 6/6 in the right eye. Left eye relative afferent pupillary defect was barely positive with mild anterior chamber reaction. Intraocular pressure was normal in both eyes (right eye: $16 \mathrm{mmHg}$ and left eye: $17 \mathrm{mmHg}$ ). Fundus examination of the left eye showed mild vitritis, swollen optic disc with macular star, crops of active choroidal lesions at superonasal retina with a linear arrangement in the form of migratory track nasally (Figure 1). However, there were no nematodes seen on fundus examination. Optical coherence tomography of the left eye showed minimal subretinal fluid at the macula with some hyperreflectivity lesions (Figure 2). Optic nerve examination showed red desaturation with reduced contrast sensitivity and impaired color vision in the left eye as compared with the right eye. Humphrey visual field on the left eye showed superior temporal field defect with enlargement of blind spot. Right eye examination was otherwise unremarkable. Her systemic examination was normal. There was no lymphadenopathy or organomegaly.

On the basis of the clinical findings with the presence of crops of choroidal lesions with migratory track, she was

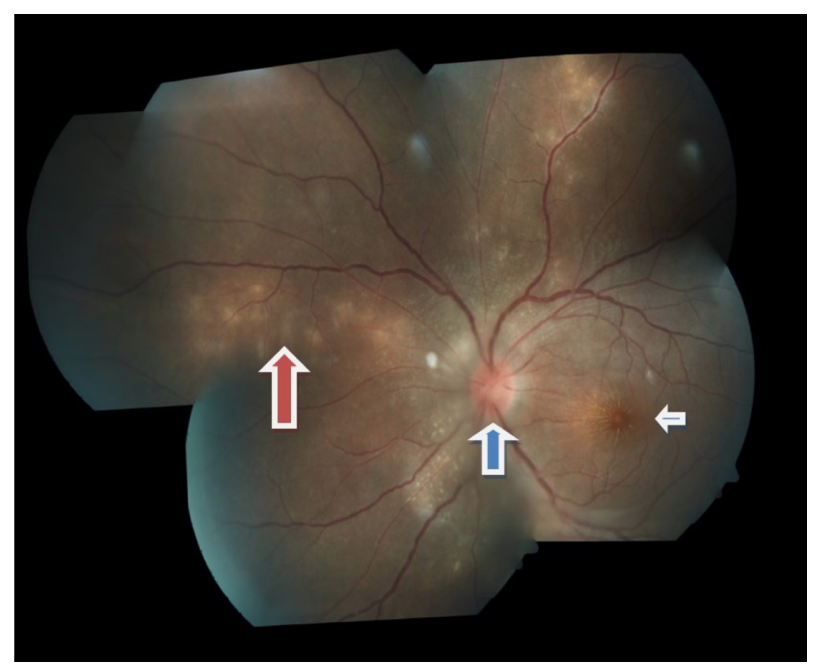

Figure I Left fundus showed swollen optic disc (blue arrow) with macular star (white arrow) and crops of active choroidal lesions at superonasal retina with a linear arrangement in the form of migratory track nasally (red arrow). treated as for presumed DUSN. Focal argon laser was given to the area of migratory track followed by oral albendazole $400 \mathrm{mg} 12$ hourly for 6 weeks. Her left eye vision improved from $6 / 12$ to $6 / 6$ at 1 week after treatment. Fundus showed resolution of vitritis, regression of optic disc swelling as well as resolution of crops of choroidal lesions, with no new active lesion (Figure 3). Repeat optical coherence tomography of the left eye showed resolution of subretinal fluid at the macula (Figure 4).

Blood investigation was done to rule out other infective causes. Her investigations showed normal full blood count with no eosinophilia, and erythrocyte sedimentation rate (ESR) was $33 \mathrm{~mm}$ per hour. Venereal Disease Research Laboratory (VDRL) serology for Burkholderia pseudomallei and Leptospira was negative. A chest radiograph was normal and Mantoux test was negative. However, immunoglobulin (Ig) M serology for Bartonella henselae was positive (titer 1:48). Based on the positive serological test, a second diagnosis of bartonellosis or CSD was made. Oral doxycycline $100 \mathrm{mg} 12$ hourly for 4 weeks was added after 2 weeks of administration of oral albendazole. Follow-up at 1 month after completion of both albendazole and doxycycline therapy showed that left eye vision acuity was stable at $6 / 6$. Fundus showed complete resolution of choroidal lesions and resolution of neuroretinitis (Figure 5). Written informed consent was obtained from the patient for the publication of the paper and the photographs. This case report was approved by the Ethics Committee of Hospital Selayang.

\section{Discussion}

So far, there have been no reports in the literature of double infection with DUSN and CSD causing neuroretinitis. Neuroretinitis affects $1 \%-2 \%$ of patients with $B$. henselae and is characterized by optic disc swelling with partial or complete macular star. ${ }^{8}$ It is caused by infection of $B$. henselae after contact with infected cat. $B$. henselae is a gram-negative, aerobic, fastidious, rod-shaped intracellular bacteria, which causes CSD or bartonellosis. ${ }^{910}$ Typically, patients present with unilateral neuroretinitis, and it may be associated with lymphadenopathy or fever. Diagnosis of CSD is based on epidemiology of exposure to cats or pets, fundus finding, and positive serology or culture of $B$. henselae. ${ }^{11,12}$

DUSN is a unilateral inflammatory disease affecting the outer retinal and the retinal pigment epithelium. Parasites of different sizes and several species of nematodes have been reported as the etiology of DUSN without conclusive evidence about the specific agent. Those parasites include Toxocara canis, Baylisascaris procyonis, and 


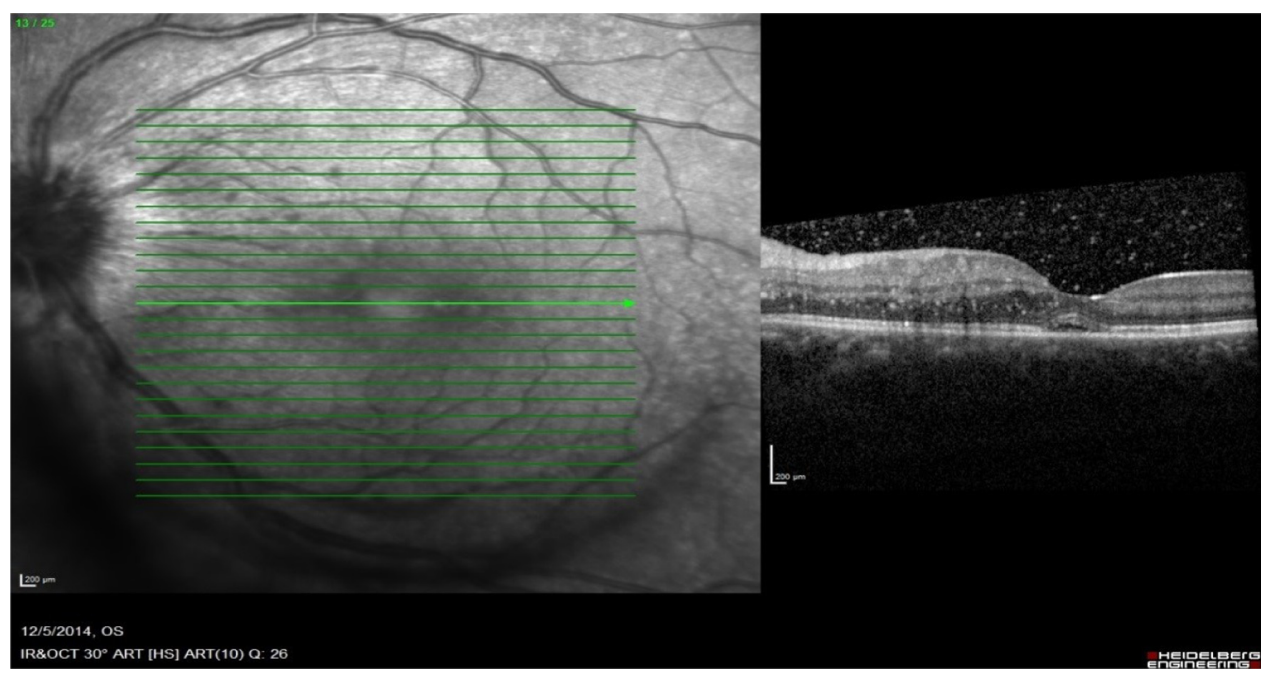

Figure 2 Optical coherence tomography of the left eye showed minimal subretinal fluid at the macula with some hyperreflectivity lesions at presentation. The scale represents the corresponding measurement of $200 \mathrm{~mm}$ vertically and horizontally.

Note: The green arrow indicates the cross-section of the macula shown by the adjacent optical coherence tomography image.

Ancylostoma caninum. Clinical characteristics are manifested in early and late stages. The early ocular findings include visual loss, vitreous cells, optic disc inflammation and leakage, and transient recurrent crops of gray-white outer retinal lesions. ${ }^{13,14}$ The late phase is characterized by optic nerve atrophy, retinal vessels narrowing, and focal or diffuse retinal pigment epithelium degeneration marked by profound visual loss. ${ }^{15,16}$ The worm can be identified in any stage of disease. However, only approximately $39 \%$ of parasites are visualized during disease presentation based on the study by de Amorim Garcia Filho et al. ${ }^{17}$ Because serologic testing has been variable, the definitive diagnosis is made when the clinical characteristics of DUSN are found, in conjunction with presence of the intraocular worm.

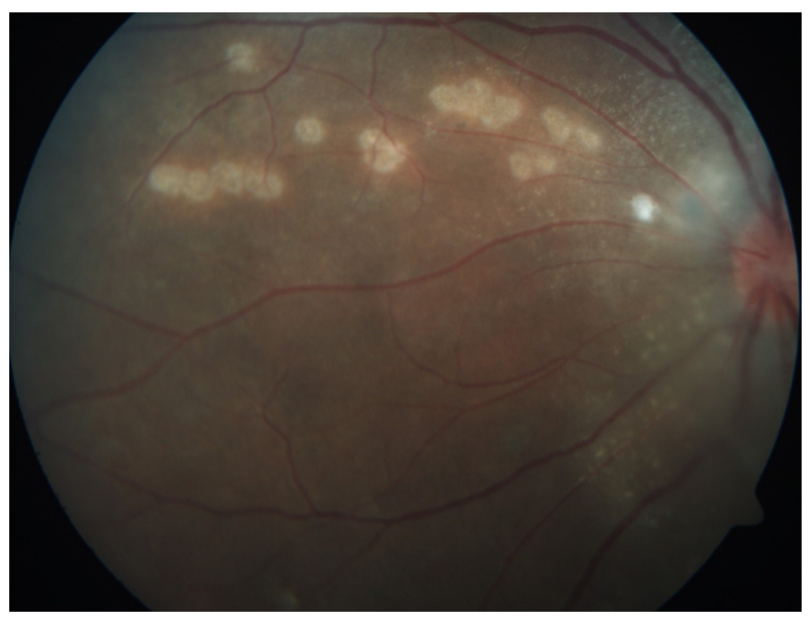

Figure 3 Left fundus showed resolution of crops of choroidal lesions with multiple focal laser scars nasal to the optic disc at I week posttreatment.
In our case, presentation of ocular finding with crops of gray-white outer retinal lesions, and migrating tracks suggest early stage of DUSN. The diagnosis of DUSN is clinically based on the crops of choroidal lesions with migratory track and its response to treatment. Later, positive IgM serology for $B$. henselae succumbs the patient to undergo dual treatment. History of contact with pets increases the susceptibility of the patient to get coinfected by two pathogens simultaneously.

Early antibiotic treatment improves visual outcome and hastens visual recovery. Recommended antibiotics for CSD include gentamycin, doxycycline, azithromycin, trimethop$\mathrm{rim} / \mathrm{sulfamethoxazole,} \mathrm{ciprofloxacin,} \mathrm{and} \mathrm{rifampicin,} \mathrm{which}$ have been reported to have good efficacy. ${ }^{18}$

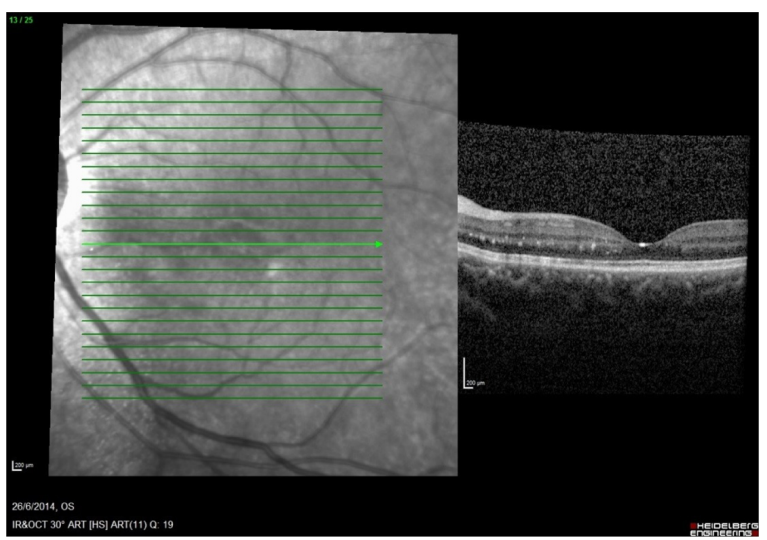

Figure 4 Optical coherence tomography of the left eye showed resolution of subretinal fluid at the macula at I week posttreatment. The scale represents the corresponding measurement of $200 \mathrm{~mm}$ vertically and horizontally.

Note: The green arrow indicates the cross-section of the macula shown by the adjacent optical coherence tomography image. 


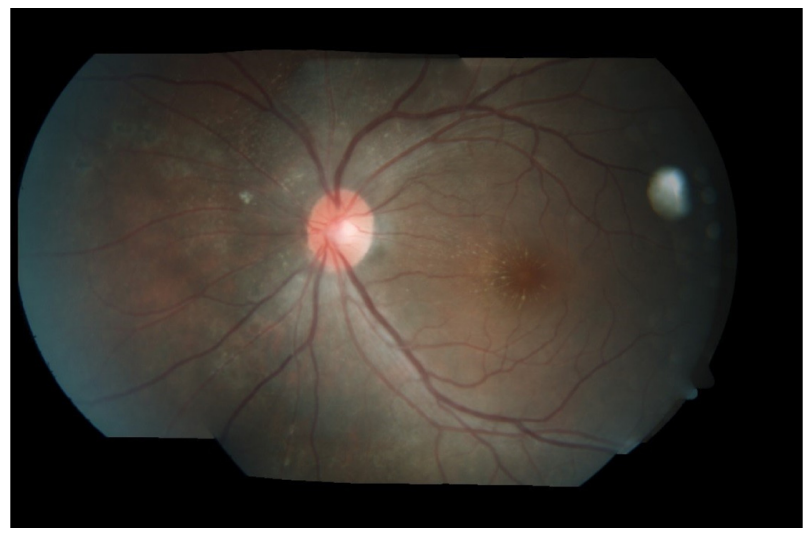

Figure $\mathbf{5}$ Left fundus showed regression of optic disc swelling with resolving macular star and resolution of crops of choroidal lesions with multiple focal laser scars nasal to the optic disc at I month posttreatment.

Photocoagulation is the treatment of choice for DUSN because it is an effective means to destroy the worm. However, locating the worm is always a difficult task. Oral treatment with albendazole may be an alternative for patients in whom the worm is not identified and in whom photocoagulation cannot be performed. ${ }^{19,20}$ Early and prompt treatment in this patient resulted in excellent recovery of vision.

\section{Acknowledgment}

The authors would like to thank the patient who has given her informed consent to participate in this case report and for the publication of her photos.

\section{Disclosure}

The authors report no conflicts of interest in this work.

\section{References}

1. Ray S, Gragoudas E. Neuroretinitis. Int Ophthalmol Clin. 2001; 41(1):83-102.

2. Leber T. Die pseudonephritischen netzhauterkrankungen, die retinitis stellata: die purtschersche netzhautaffektion nack schwerer schadelverletzung. In: Graefe AC, Saemische T, editors. Graefe-Saemisch Handbuch der Augerheilkunde. 2nd ed. Leipzig, Germany: Engelmann; 1916:1319.

3. Gass JD. Diseases of the optic nerve that may simulate macular disease. Trans Sect Ophthalmol Am Acad Ophthalmol Otolaryngol. 1977;83: 763-770.
4. Walsh FB, Hoyt WF. Neuroretinitis. In: Clinical Neuro-Ophthalmology. 3rd ed. Baltimore, MD: Williams \& Wilkins Co; 1982:234-235.

5. Fish RH, Hoskins JC, Kline LB. Toxoplasmosis neuroretinitis. Ophthalmology. 1993;100(8):1177-1182.

6. Duke-Elder S, Dobree JH. Diseases of the retina. In: Duke-Elder S, editor. System of Ophthalmology. London: Henry Kimpton; 1967;10: 126-127.

7. Bird AC, Smith JL, Curtin VT. Nematodes optic neuritis. Am J Ophthalmol. 1970;69(1):72-77.

8. Terrada C, Bodaghi B, Conrath J, Raoult D, Drancourt M. Uveitis: an emerging clinical form of Bartonella infection. Clin Microbiol Infect. 2009;15(Suppl 2):132-133.

9. Bergman AM, Groothedde JW, Schellekens JF, van Embden JD, Ossewaarde JM, Schouls LM. Etiology of catscratch disease: comparison of polymerase chain reaction detection of Bartonella and Afipia felis DNA with serology and skin tests. J Infect Dis. 1995;171(4):916-923.

10. Regnery R, Tappero J. Unraveling mysteries associated with cat-scratch disease, bacillary angiomatosis, and related syndromes. Emerg Infect Dis. 1995;1(1):16-21.

11. Raihan AR, Zunaina E, Wan-Hazabbah WH, Adil H, Lakana-Kumar T. Neuroretinitis in ocular bartonellosis: a case series. Clin Ophthalmol. 2014;8:1459-1466.

12. Suhler EB, Lauer AK, Rosenbaum JT. Prevalence of serologic evidence of cat scratch disease in patients with neuroretinitis. Ophthalmology. 2000;107(5):871-876.

13. Gass JD, Scelfo R. Diffuse unilateral subacute neuroretinitis. $J R$ Soc Med. 1978;71(2):95-111.

14. Gass JD. Diffuse unilateral subacute neuroretinitis. In: Stereoscopic Atlas of Macular Disease: Diagnosis and Treatment. 4th ed. St Louis, MO: Mosby; 1997:622-628.

15. Garcia CA, Gomes AH, Garcia Filho CA, Vianna RN. Early-stage diffuse unilateral subacute neuroretinitis: improvement of vision after photocoagulation of the worm. Eye (Lond). 2004;18(6):624-627.

16. Garcia CA, Gomes AH, Vianna RN, Souza Filho JP, Garcia Filho CA, Orefice F. Late-stage diffuse unilateral subacute neuroretinitis: photocoagulation of the worm does not improve the visual acuity of affected patients. Int Ophthalmol. 2005;26:39-42.

17. de Amorim Garcia Filho CA, Gomes AH, de A Garcia Soares AC, de Amorim Garcia CA. Clinical features of 121 patients with diffuse unilateral subacute neuroretinitis. Am J Ophthalmol. 2012;153(4):743-749.

18. Rolain JM, Brouqui P, Koehler JE, Maguina C, Dolan MJ, Raoult D. Recommendations for treatment of human infections caused by Bartonella species. Antimicrob Agents Chemother. 2004;48(6):1921-1933.

19. Souza EC, Casella AM, Nakashima Y, Monteiro ML. Clinical features and outcomes of patients with diffuse unilateral subacute neuroretinitis treated with oral albendazole. Am J Ophthalmol. 2005; 140(3):437-445.

20. Guan-Fook N, Hayati AA, Raja-Azmi MN, Liza-sharmini AT, Wan-Hazabbah WH, Zunaina E. Diffuse unilateral subacute neuroretinitis in a young boy: a case report. Clin Ophthalmol. 2012;6:487-490.

\section{Publish your work in this journal}

The International Medical Case Reports Journal is an international, peer-reviewed open-access journal publishing original case reports from all medical specialties. Previously unpublished medical posters are also accepted relating to any area of clinical or preclinical science. Submissions should not normally exceed 2,000 words or
4 published pages including figures, diagrams and references. The manuscript management system is completely online and includes a very quick and fair peer-review system, which is all easy to use. Visit $\mathrm{http}: / / \mathrm{ww} w$. dovepress.com/testimonials.php to read real quotes from published authors. 